\title{
cdc2 phosphorylation is required for its interaction with cyclin
}

\author{
Bernard Ducommun ${ }^{1}$, Paolo Brambilla ${ }^{1,4}$, \\ Marie-Anne Félix ${ }^{2}$, B.Robert Franza $\mathrm{Jr}^{3}$, \\ Eric Karsenti ${ }^{2}$ and Giulio Draetta ${ }^{1}$

\begin{abstract}
${ }^{1}$ Differentiation and ${ }^{2}$ Cell Biology Programmes, European Molecular Biology Laboratory, Meyerhofstrasse 1, D-6900 Heidelberg, FRG and ${ }^{3}$ Cold Spring Harbor Laboratory, Cold Spring Harbor, NY 11724, USA

${ }^{4}$ Permanent address: USSL 63, Ospedale di Desio, 20033 Desio, Italy
\end{abstract} \\ Communicated by S.A.Courtneidge
}

Activation of the cdc 2 protein kinase at different stages of the cell cycle is regulated by post-translational modifications and interactions with cyclins. We show that in vitro translated human cdc2 binds very poorly to $A$ and $B$ cyclins, unless it has been preincubated with a Xenopus egg extract. This results in the phosphorylation of cdc2 which allows binding to cyclins. The replacement of Thr161, a residue conserved and phosphorylated in other protein kinases, with valine inhibits cdc2 association with $A$ and $B$ cyclins. In addition, mutations in the amino-terminus of cdc2 and within the conserved 'PSTAIR' region strongly inhibit binding. The Thr161Val mutation causes a lethal phenotype in the fission yeast Schizosaccharomyces pombe, while replacement of Thr161 with glutamic acid, potentially mimicking phosphorylation, causes uncoordination of mitosis and multiple cytokinesis. These results suggest that a threonine phosphorylation/dephosphorylation cycle is involved in regulating cdc2 function.

Key words: cdc2 protein kinase/cyclin/phosphorylation

\section{Introduction}

The cdc2 protein kinase is a universal cell cycle regulator. The ordered occurrence of cell cycle events in all eukaryotic cells appears to be governed by factors which activate specific forms of cdc 2 . In fact cdc 2 can be considered as an essential switch which can be turned on and off in response to specific cellular signals. Its binding to a set of molecules called cyclins leads to the activation of different cdc2 kinase activities. Cyclins were initially identified in oocytes and eggs of marine invertebrates (for review, see Hunt, 1989), and are operationally defined as proteins that vary in abundance during the cell cycle, contain characteristic sequences including the so-called 'cyclin box', and interact and activate the cdc 2 catalytic subunit. Cyclins have been cloned from a large variety of organisms. On the basis of their sequence similarities they can be grouped in three classes: A cyclins, B cyclin and CLN cyclins. The timing of appearance of cyclin kinases in the cell cycle differs. The cyclin B kinase complex is activated just before mitosis, while in contrast A cyclins bind and activate cdc 2 earlier in the cell cycle, in $\mathrm{S}$ and $\mathrm{G}_{2}$ (Giordano et al., 1989; Minshull et al., 1990; Pines and Hunter, 1990). CLN cyclins act in the $G_{1}$ phase of the cell cycle in Saccharomyces cerevisiae (Richardson et al., 1989). A number of laboratories have characterized in detail a complex of cdc2 and B type cyclins called Maturation Promoting Factor (MPF) (Gautier et al., 1990; Labbé et al., 1989b), which is activated at the end of $\mathrm{G}_{2}$ and drives cells into mitosis (Ducommun et al., 1990; Labbé et al., 1989a).

The regulation of the cdc 2 kinase does not involve oscillations in the cdc 2 protein levels, since its total amount appears to be constant during the various phases of the cycle in somatic cells (Draetta and Beach, 1988; Simanis and Nurse, 1986) as well as during the highly synchronous divisions of early embryonic cells (Draetta et al., 1989). On the other hand the phosphorylation of cdc2 changes during the cell cycle (Draetta and Beach, 1988; Draetta et al., 1988; Gautier et al., 1989; Gould et al., 1990; Gould and Nurse, 1989; Krek and Nigg, 1991). In mammalian cells, fission yeast and Xenopus oocytes, the tyrosine dephosphorylation of cdc2 parallels its activation (Dunphy and Newport, 1989; Gould et al., 1990; Gould and Nurse, 1989; Morla et al., 1989). Moreover, in vitro tyrosine dephosphorylation activates the cdc2 kinase (Jessus et al., 1990; Pondaven et al., 1990). Recently, it has been shown that, in Xenopus egg extracts, binding of cdc 2 to cyclin is accompanied by tyrosine phosphorylation which keeps cdc2 transiently inactive (Solomon et al., 1990). In fission yeast, tyrosine phosphorylation on cdc2 prevents the premature occurrence of mitosis before DNA replication has been completed. Indeed, substitution of this tyrosine by phenylalanine advances cells prematurely into mitosis, and renders them unable to arrest in response to drugs which inhibit DNA synthesis (Gould et al. , 1990). The role of other post-translational modifications of cdc 2 on its function has not yet been investigated in detail. In this work, we analyse the structural features of the cdc 2 molecule that are required for tight binding to cyclins. Our findings show that phosphorylation is required for association of cdc 2 with cyclins. Moreover, in addition to conserved amino acid clusters in the cdc 2 molecule, a phosphorylation site required for cdc2 gene function, Thr161, is essential for cyclin binding. These results suggest the existence of an additional level of regulation of the cdc2 kinase activity, i.e. a phosphorylation-dependent association with cyclin.

\section{Results}

\section{In vitro association of human cdc2 with cyclins $A$ and $B$}

In order to define the requirements for cdc2 binding to cyclins, we synthesized human cdc 2 by in vitro transcription and subsequent RNA translation. The results shown in Figure 1A (lane 1) identify a $\mathrm{M}_{\mathrm{r}} 34000$ band as the $c d c 2$ gene product. In addition, lower apparent molecular mass 
proteins were generated. They corresponded to internal initiation sites of translation at methionine residues 32,71 , 85 and 100, producing species of $30654,26200,24456$ and $22706 \mathrm{Da}$ respectively. All these species could be precipitated with the anti-human cdc2 carboxy-terminal peptide antiserum G6 (Draetta and Beach, 1988). In order to test whether in vitro translated cdc 2 could bind cyclin, the translation mixture was incubated with cyclin A-Sepharose for $30 \mathrm{~min}$ at $25^{\circ} \mathrm{C}$ in buffer A (see Materials and methods). This reagent was obtained by coupling purified recombinant bacterially expressed cyclin A to Sepharose beads (M.Pagano and G.Draetta, in preparation). As shown in Figure 1, the amount of cdc2 recovered in the cyclin A-Sepharose pellet (Figure 1A, lane 4) was only slightly higher than that precipitated with control BSA-Sepharose (Figure 1A, lane 2).

Since our purified recombinant human cyclin A was able to bind cdc2 and activate histone H1 kinase in Xenopus egg extracts (M.A.Félix and P.Clarke, unpublished) we were convinced that this protein was biologically active. We therefore examined whether an activity in the frog egg extract could stimulate the interaction between cdc 2 and cyclin. We incubated cdc2 with cyclin A-Sepharose in the presence of an interphase Xenopus extract prepared 40 min after egg activation (Félix et al., 1990a) and depleted of endogenous cdc2 and A and B cyclins, using p13-Sepharose (see Materials and methods). As shown in Figure 1A, lane 3, the addition of a Xenopus egg extract led to a significant increase ( $\sim$ - to 5-fold) in the extent of binding of cdc2 to cyclin A-Sepharose. Between 50 and $70 \%$ of the added cdc2 was bound to cyclin A-Sepharose. Binding of the faint $30 \mathrm{~K}$ amino-terminal truncated form of cdc2 was not stimulated by the addition of Xenopus extracts, therefore its binding is probably due to non-specific carry-over. We were interested in testing whether the incubation with a cell extract was also required for cyclin B binding to $\operatorname{cdc} 2$. Since we could not express cyclin B in large amounts in bacteria, we
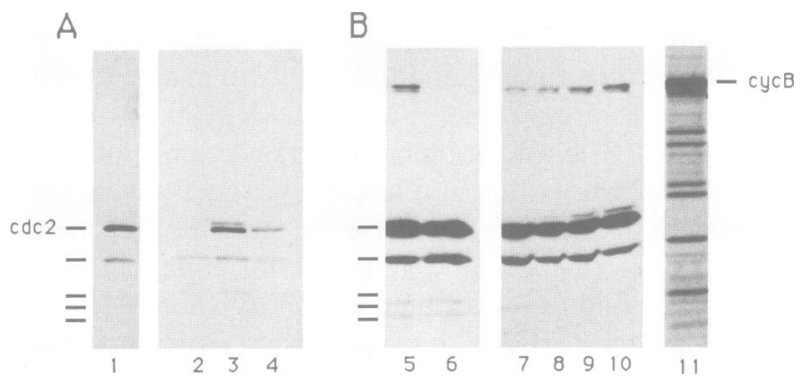

Fig. 1. Binding of cdc2 to cyclins $A$ and $B$ depends on the addition of a Xenopus egg extract. (A) cdc2 binding to cyclin A-Sepharose. (Lane 1) In vitro translation of human $c d c 2$ showing the major product and N-terminal truncated forms corresponding to internal initiation sites of human $c d c 2$ translation at methionine residues 1, 32, 71, 85 and 100. In vitro translated cdc 2 was incubated in the presence of cyclin A-Sepharose (lanes 3 and 4) or BSA-Sepharose (lane 2), and control buffer (lane 4) or Xenopus extract (lanes 2 and 3) at $25^{\circ} \mathrm{C}$ for $30 \mathrm{~min}$. After washing, the cdc2 bound to cyclin A-Sepharose was subjected to SDS-PAGE and autoradiographed without enhancing. (B) cdc2 binding to cyclin $\mathrm{B}$. Human cdc2 and in vitro translated human cyclin B (lane 11) were incubated together in the presence (lanes 5 and $7-10$ ) or in the absence (lane 6) of Xenopus extract for $30 \mathrm{~min}$ (lane 5 ) or for increasing times (lanes 7-10, respectively, 5, 10, 20 and $30 \mathrm{~min})$ at $25^{\circ} \mathrm{C}$. The level of cyclin B co-immunoprecipitated with human cdc2 was analysed by SDS-PAGE on a 7.5-15\% gradient gel. The gel was treated with Enlightning (NEN) prior to exposure. decided to use in vitro translated protein (Figure $1 \mathrm{~B}$, lane 11). Cyclin B was co-immunoprecipitated with human cdc2 using the $\mathrm{G} 6$ antiserum, following incubation in the presence (Figure 1B, lane 5) or in the absence of Xenopus egg extract (Figure 1B, lane 6). The association between cyclin B and cdc2 increased as a function of the incubation time in the egg extract (Figure 1B, lane 7-10), but the amount of cyclin $\mathrm{B}$ associated to $\mathrm{cdc} 2$ remained low compared with the amount of precipitated cdc2. Because of the low sensitivity of this cyclin B assay, the powerful cyclin A-Sepharose reagent was used in most subsequent experiments.

We suspected that phosphorylation of cdc2 was important for its binding to cyclin. Therefore, we examined the effects of a number of agents known to inhibit protein kinases or phosphatases, on cyclin binding to cdc2 in egg extracts (Figure 2A). The enhancement of the binding of cdc2 to cyclin $\mathrm{A}-$ Sepharose was inhibited up to $75 \%$ by EDTA (Figure 2A, lane 6), 80\% by staurosporine (data not shown) and $100 \%$ by the ATP analogue, p-fluorosulfonylbenzoyl adenosine (FSBA) (Figure 2A, lane 3). This latter reagent is a specific, irreversible inhibitor of protein kinases, which acts by forming a stable bond with a lysine residue necessary for catalysis (Zoller et al., 1981). By contrast, okadaic acid, a powerful inhibitor of protein phosphatases 1 and $2 \mathrm{~A}$, and sodium orthovanadate, a tyrosine phosphatase inhibitor, did not affect binding when added to the reaction (Figure 2B, lanes 4-6). We obtained similar results when cyclin B binding was tested (data not shown). These results suggested that phosphorylation events occurring during the incubation
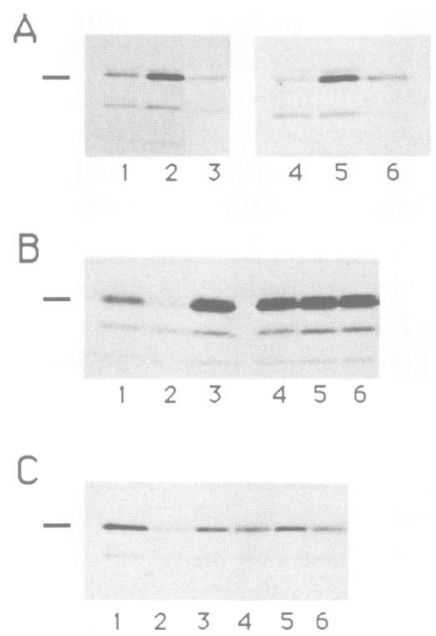

Fig. 2. Effects of kinase and phosphatase inhibitors on cdc2 binding to cyclin A. (A) cdc2 was incubated $\left(30 \mathrm{~min}\right.$ at $\left.25^{\circ} \mathrm{C}\right)$ in the presence of cyclin A-Sepharose (lanes 1-6), and control buffer (lanes 1 and 4) or Xenopus extract (lanes 2, 3,5 and 6). $1 \mathrm{mM}$ FSBA (lane 3) or $10 \mathrm{mM}$ EDTA (lane 6) were added to the reaction. After washing, bound material was electrophoresed on $12.5 \%$ polyacrylamide gel and exposed to film without enhancing. (B) cdc2 was incubated $(30 \mathrm{~min}$ at $25^{\circ} \mathrm{C}$ ) in the presence of cyclin $\mathrm{A}-$ Sepharose (lanes $1,3-6$ ) or BSA-Sepharose (lane 2) and control buffer (lane 1) or Xenopus extract (lanes 2-6) for $30 \mathrm{~min} .1 \mu \mathrm{M}$ okadaic acid (lane 4) or $1 \mathrm{mM}$ sodium orthovanadate (lane 5) or both (lane 6) were added to the reaction. (C) cdc2 was incubated in the presence of Xenopus extract (lanes 2-6) or buffer (lane 1) for $30 \mathrm{~min}$ at $25^{\circ} \mathrm{C}$. $1 \mu \mathrm{M}$ okadaic acid (lane 4) or $1 \mathrm{mM}$ sodium orthovanadate (lane 5) or a mixture of both (lane 6) were added to the reaction mixture. After addition of $10 \mathrm{mM}$ EDTA, cyclin A-Sepharose (lanes 1, 3-6) or BSA-Sepharose (lane 2) were added and the incubation continued for an additional $60 \mathrm{~min}$ before precipitation. The bound material was electrophoresed on a $12.5 \%$ polyacrylamide gel and exposed to film without enhancing. 
of cdc2 and cyclins with a Xenopus egg extract were required for the interaction. To test whether binding could occur when cdc2 was pretreated with the Xenopus extract in the absence of cyclin, we preincubated in vitro translated cdc2 with an egg extract for $30 \mathrm{~min}$ at $25^{\circ} \mathrm{C}$ in the absence of cyclin A.



Fig. 3. Effect of mutating cdc2 phosphorylation sites on cyclin-cdc2 binding. (A) In vitro translated wild-type cdc2 (lane 1), Y15F (lane 2) and T161V (lane 3) cdc2 mutant proteins were incubated in the presence of cyclin A-Sepharose and Xenopus extract at $25^{\circ} \mathrm{C}$ for 30 min. After washing, bound cdc2 was analysed after electrophoresis on $12.5 \%$ polyacrylamide gel and autoradiography. (B) In vitro translated wild-type cdc2 (lane 1), Y15F (lane 2) and T161V (lane 3) cdc2 mutant proteins were incubated in the presence of in vitro translated cyclin B and Xenopus extract at $25^{\circ} \mathrm{C}$ for $30 \mathrm{~min}$. Human cdc2 was specifically immunoprecipitated with $\mathrm{G} 6$ antiserum. The level of cyclin B associated to cdc2 was examined after SDS-PAGE and fluorography using Enlightning (NEN).
Cyclin A-Sepharose was then added to the reaction mixture after inhibition of kinase activities with EDTA (Figure 2C). The material retained by cyclin A-Sepharose was analysed after a further 60 min incubation. As shown in Figure 2B and $C$ (lanes 1-3), no stimulation of cdc2 binding to cyclin $A$ was observed under these conditions. The converse experiment was also performed: i.e. cyclin A-Sepharose was preincubated with the Xenopus extract, kinase activities were stopped with FSBA and the pelleted beads washed prior to the addition of in vitro translated cdc2. Under these conditions we did not detect any stimulation of the binding (data not shown).

There are several possible explanations for this phenomenon. The lack of cyclin binding could have been due to the presence of a very active phosphatase in the egg extract, which would prevent cdc2 phosphorylation in the absence of cyclin. Alternatively, binding of the cyclin to phosphorylated cdc2 would prevent its dephosphorylation. To test this hypothesis, phosphatase inhibitors were added during the preincubation of cdc2 with the egg extract in the absence of cyclin A-Sepharose. This treatment did not improve cdc2 binding (Figure 2C, lanes 3-6). This last result suggests that the phosphorylation event needed for the binding between cdc2 and cyclin occurs only in the presence of cyclin or that a protein phosphatase insensitive to the inhibitors used is involved (see Discussion).

When cdc2 was incubated in the presence of cyclin A and Xenopus egg extract, a fraction of the cdc2 molecules had a higher apparent molecular weight on SDS gels. This

Table I. In vitro and in vivo properties of cdc2 mutants

\begin{tabular}{|c|c|c|c|}
\hline Sequence & $\begin{array}{l}\text { Cyclin A } \\
\text { binding }^{\mathrm{f}} \\
(\%)\end{array}$ & $\begin{array}{l}\text { Wild-type } \\
\text { straing }\end{array}$ & $c d c 2-33$ straing $^{8}$ \\
\hline Wild-type & 100 & wee & wee + elongated $^{\mathrm{a}}$ \\
\hline $\mathrm{E} 2 \mathrm{~A}, \mathrm{D} 3 \mathrm{~A}, \mathrm{~K} 6 \mathrm{~A}$ & 105 & n.d. ${ }^{\mathrm{e}}$ & n.d. ${ }^{e}$ \\
\hline E8A,K9A,E12A & 18 & wee & wee + elongated ${ }^{a}$ \\
\hline $\mathrm{K} 20 \mathrm{~A}, \mathrm{R} 22 \mathrm{~A}, \mathrm{H} 23 \mathrm{~A}, \mathrm{~K} 24 \mathrm{~A}$ & 134 & wt & $\mathrm{wt}+c d c^{-}$ \\
\hline $\mathrm{K} 33 \mathrm{~A}, \mathrm{~K} 34 \mathrm{~A}, \mathrm{R} 36 \mathrm{~A}$ & 13 & wt + elongated & $c d c^{-}$ \\
\hline $\mathrm{E} 38 \mathrm{~A}, \mathrm{E} 40 \mathrm{~A}, \mathrm{E} 41 \mathrm{~A}, \mathrm{E} 42 \mathrm{~A}$ & 13 & $w t+$ elongated & $c d c^{-}$ \\
\hline R50A,E51A & 0 & wt & $c d c^{-}$ \\
\hline K56A,E57A,R59A,H60A & 75 & wt + elongated & $c d c^{-\mathrm{b}}$ \\
\hline D68A,D71A,R73A & 82 & wee & wee \\
\hline D86A,K88A,K89A,D92A & 54 & wee & wee + multiseptated \\
\hline R158A,H162A,E163A & 90 & wt & $\mathrm{wt}+c d c^{-}$ \\
\hline R170A,E173A & 110 & wt & $c d c^{-\mathrm{b}}$ \\
\hline R180A,D186A & 105 & $w t$ & $c d c^{-\mathrm{b}}$ \\
\hline H205A,D207A,E209A,D211A & 60 & wt & wee + elongated $^{\mathrm{a}}$ \\
\hline R215A,R218A & 78 & wt & $c d c^{-\mathrm{b}}$ \\
\hline $\mathrm{D} 271 \mathrm{~A}, \mathrm{~K} 274 \mathrm{~A}, \mathrm{R} 275 \mathrm{~A}$ & 101 & wt & $c d c^{-\mathrm{b}}$ \\
\hline S277A & 100 & wee & wee \\
\hline $\mathrm{T} 14 \mathrm{~A}$ & 126 & wt & $c d c^{-c}$ \\
\hline Y15F & 97 & wee + m.c..$^{d}$ & wee + elongated $^{\mathrm{a}}$ \\
\hline T161E & 9 & elongated/multiseptated & $c d c^{-}$ \\
\hline T161V & 5 & $c d c^{-}$ & $c d c^{-}$ \\
\hline
\end{tabular}

${ }^{a}$ The presence of a few elongated cells was probably due to plasmid loss.

${ }^{b}$ Mutant showing a defective interaction with sucl in vitro (Ducommun,B., Brambilla,P. and Draetta,G. submitted).

${ }^{\mathrm{c}}$ The reasons for this phenotype are not known at present.

${ }^{\mathrm{d}}$ Mitotic catastrophe.

${ }^{\mathrm{c}}$ Not done.

${ }^{\mathrm{f}}$ Normalized to the amount of precipitable cdc2 (anti-C terminus antibodies) and to an arbitrary value of $100 \%$ binding in the wild-type (see Materials and methods). Averages of two to three determinations for each mutant.

$\mathrm{g}_{\mathrm{g}} \mathrm{dc} 2$ mutations affecting the binding of cyclin to cdc2 were cloned in the pREP42 inducible expression vector (G.Basi et al., in preparation), and transformed into SP200 (wild-type strain) and SP356 ( $c d c 2-33$ ts strain) cells. Cell phenotypes were observed 20 and $26 \mathrm{~h}$ after promoter induction, respectively. 
upward shift was consistently found both for cyclin A-Sepharose bound cdc2 (see for example Figure 1A, lane 3 ; Figure 2B, lanes 3-6) and for cdc2 bound to in vitro translated cyclin B (Figure $1 \mathrm{~B}$, lane 10 ). It was previously found that phosphorylation of cdc 2 causes an increase in its apparent mol. wt on SDS-PAGE (Draetta and Beach, 1988), and that two of the three upper bands normally observed upon phosphorylation on SDS-PAGE contain phosphotyrosine.

\section{Integrity of Thr161 is required for cyclin binding}

The above results prompted us to examine in detail the effects of cdc2 phosphorylation on its binding to the cyclins. It is known that cdc2 is periodically phosphorylated and dephosphorylated during the cell cycle (Draetta and Beach, 1988; Krek and Nigg, 1991; Morla et al., 1989). In fission yeast, cdc2 is phosphorylated on Tyr15 (Gould and Nurse, 1989), a residue located within the ATP binding site, and on threonine 167 (K.Gould and P.Nurse, personal communication). In vertebrates, cdc2 is phosphorylated on serine, threonine and tyrosine residues (Draetta et al., 1988). Major phosphorylation sites have been identified in chicken cdc2 as Thr14, Tyr15 and Ser277 (Krek and Nigg, 1991). Phosphorylation of Thr161 (the homologous residue of yeast Thr 167) has been tentatively identified. Similar results have been obtained in mouse cells (C.Norbury, J.Blow and P.Nurse, personal communication). These sites are all located within sequences that are highly conserved among the cdc 2 proteins of a large variety of species. We tested the effects of mutating these phosphorylation sites on the in vitro binding of cdc 2 to cyclin $A$ and $B$, in the presence of a Xenopus egg extract (Figure 3A and B respectively). Whereas substitutions of Thr14, Ser277 or Tyr15 with non-phosphorylatable residues did not affect the binding (lanes 2; see Table I for Ser277 and Thr14), substitution of Thr161 with a valine completely abolished the binding of cdc2 to cyclins (lanes 3). Mutation of Tyr15 to a phenylalanine also eliminated the electrophoretic shift of cdc2 (compare Figure 3A, lanes 1 and 2), confirming that the phosphorylation of this residue was responsible for the mobility change we observed.

In order to demonstrate that incubation of cdc 2 with the Xenopus egg extracts led to the appearance of phosphorylated forms of cdc2, and that cyclin A was selectively binding to phosphorylated form(s) of cdc2, we analysed the products of such reactions by two-dimensional gel electrophoresis (Garrels, 1983). When samples of the in vitro translated wildtype cdc 2 protein were run on 2-D gels, only one major isoform was identified (Figure 4, panel A, spot 1). As a reference we used the $M_{r} 30000$ truncated cdc2, which did not undergo charge shifts in the isoelectrofocusing dimension. Incubation of cdc 2 with the Xenopus egg extract, but in the absence of cyclin, did not lead to major electrophoretic changes (Figure 4, panel B). Upon incubation of wild-type cdc2 with Xenopus egg extract in the presence of cyclin $\mathrm{A}$, three major and two minor new isoforms were generated (Figure 4, panel C, spots 2, 3, 4, 5 and 6). Panel E shows a schematic view of the generated cdc2 isoforms. Two phosphorylated forms of cdc 2 (panel D, spots 2 and 6) were preferentially bound to cyclin A-Sepharose,

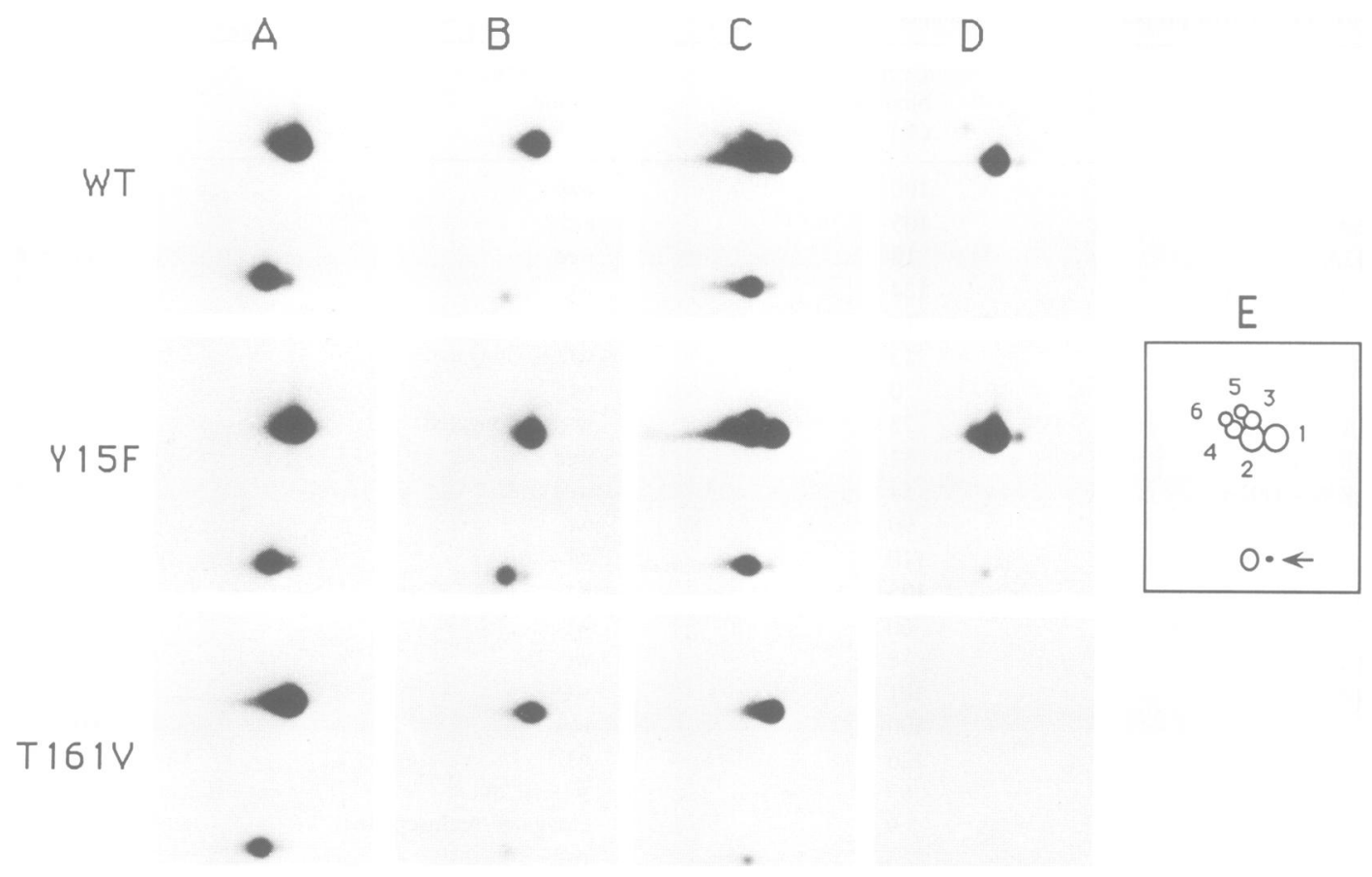

Fig. 4. Two-dimensional electrophoresis of phosphorylation site mutants of cdc2. (A) In vitro translation products of wild-type cdc2, cdc2-Y15F and cdc2-T161V mutants. This area of the 2-D gels shows the full length product of the $c d c 2$ gene (spot 1, panel E) and the first internal initiation site product (two spots of $\mathrm{M}_{\mathrm{r}} 30000$, black arrowhead, panel E). (B) In vitro translated cdc2 wild-type, cdc2-Y15F and cdc2-T161V were incubated with Xenopus extract at $25^{\circ} \mathrm{C}$ for $30 \mathrm{~min}$ in the absence of added cyclin. The entire reaction mixture was analysed. (C) In vitro translated wild-type cdc2, cdc2-Y15F and cdc2-T161V were incubated in the presence of cyclin A-Sepharose and Xenopus extract at $25^{\circ} \mathrm{C}$ for 30 min. The whole reaction mixture was analysed. (D) In vitro translated cdc2 wild-type, Y15F and T161V were incubated in the presence of cyclin A-Sepharose and Xenopus extract at $25^{\circ} \mathrm{C}$ for $30 \mathrm{~min}$. The material retained on the Sepharose beads was analysed. (E) Schematic representation of the spots generated $(2-6)$ when human cdc2 was incubated with Xenopus extract in the presence of cyclin A. The $\mathrm{M}_{\mathrm{r}} 30000$ spot (arrow) was not subjected to posttranslational modifications and should be used as a reference for horizontal alignment of the spots in the different panels. The acidic site of the IEF is on the left. 
whereas the unmodified form (spot 1) was poorly retained. The Y15F and T161V mutant proteins were also analysed by 2-D gel electrophoresis under the same conditions (Figure 4 , middle and lower panels). When the Y15F mutant protein was used, only three new isoforms (spots 2, 3 and 4) were generated upon incubation with Xenopus extract in the presence of cyclin A (panel C). Spots 5 and 6 were missing and therefore probably correspond to the tyrosine phosphorylated forms. Binding to cyclin A occurred normally with a selection for spot 2 (panel D), which could correspond to phosphorylation on Thr161. In the Thr161 mutant, phosphorylation did not occur, no new spots appeared (panel C) and there was no binding to cyclin (panel D).

Interestingly, incubation of wild-type cdc2 and mutant proteins with egg extracts but in the absence of cyclin A (Figure 4, panels B) did not cause phosphorylation of cdc2. Only the spot 1 was present, again suggesting either that binding to cyclin was needed for cdc2 phosphorylation or that cdc2 was dephosphorylated in the extract, unless bound to cyclin (see Discussion).

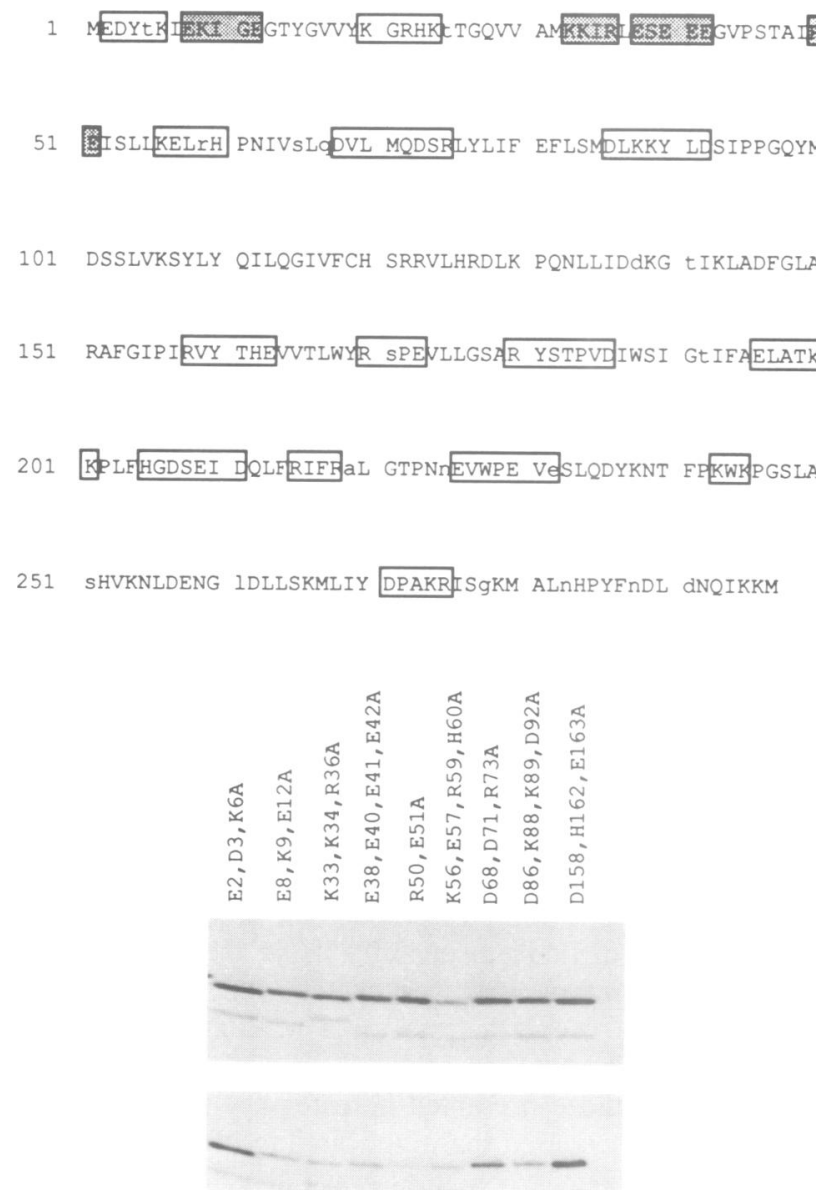

Fig. 5. Charged $\rightarrow$ alanine scanning mutagenesis of cdc2. (A) Scheme of the clusters in which charged residues (Arg, Lys, His, Asp, Glu) were changed to Ala. Shadowed boxes represents mutations that severely affected in vitro binding between cdc2 and cyclins A and B. (B) In vitro translated cdc2 mutants (as numbered) were incubated in the presence of cyclin A-Sepharose and Xenopus extract at $25^{\circ} \mathrm{C}$ for $30 \mathrm{~min}$. The bound material was analysed by SDS - PAGE (bottom panel). For each mutant, a similar amount of translation reaction was immunoprecipitated (top panel) with G6 antibodies (anti-human cdc2 carboxy-terminus). The retained material was subjected to $12.5 \%$ SDS-PAGE and autoradiographed without enhancing.

\section{Other mutations affecting cyclin-cdc2 binding}

It is essential to characterize the cdc2 domains involved in the interaction with regulatory subunits in order to understand how this kinase is regulated. In particular it is important to understand why the cdc2 kinase seems to be inactive as a monomer and whether some domains inhibit the catalytic activity in the absence of cyclin. We decided to use a scanning mutagenesis method to analyse the cyclin binding sites on the cdc2 molecule. This method has been previously used successfully to identify sites involved in the binding of the catalytic subunit of cAMP-dependent protein kinase to its regulatory subunit (Gibbs and Zoller, 1991). The alanine scanning mutagenesis method has also proved to be very useful in other studies on protein - protein interactions (Ashkenazi et al., 1990; Cunningham and Wells, 1989). In each of the clusters boxed in Figure 5A, charged amino acids (Glu, Asp, His, Arg, Lys) were mutagenized to alanine. We chose to substitute charged residues since some of them are likely to be exposed on the surface of the protein and to be involved in reversible interactions with the other protein subunits. Alanine is an abundant amino acid and does not impose sterical or electrostatic effects on neighbouring side chains (Cunningham and Wells, 1989), suggesting that substitution of charged amino acids with alanine should not affect the overall protein structure. We substituted charged amino acids in regions conserved in all cdc2 functional homologues (a functional homologue is defined by its ability to rescue in vivo a yeast strain carrying a temperature sensitive mutation of $c d c 2$ ). In addition to those indicated in Figure 5A, some other mutants were generated but they could not be tested for binding since they did not give rise to detectable translated protein. This might be due to inefficient translation and/or instability of the products.

In Figure 5B examples of the binding assay are shown. A quantitative estimate of the results of the binding assay is proposed in Table I. In order to quantify the binding of cdc2 to cyclin A, the amount of cdc2 protein precipitated with cyclin A-Sepharose was compared with the amount of in vitro translated protein added to the assay and immunoprecipitated with a specific antibody. For each mutant protein, the ratio between cyclin A-bound cdc2 and total cdc2 was normalized to a $100 \%$ value assigned to the binding of the wild-type protein. Therefore, this calculation defines a relative estimate of the binding between $\mathrm{cdc} 2$ and cyclin $\mathrm{A}$. From such analysis we identified several important areas in the cdc2 protein required for binding to cyclin A (Table I). Similar results were qualitatively obtained when binding to cyclin B was tested (data not shown). In the amino-terminal portion of the cdc2 protein, mutations (E8A, K9A, E12A; K33A, K34A, R36A; E38A, E40A, E41A, E42A) surrounding the ATP-binding site [regions I and II according to Hanks et al. (1988)] inhibited binding. E38A, E41A, E42A and R50A, E51A lie within a conserved region present in all of the functional cdc2 homologues identified so far. Amongst all of the other mutants analysed no additional cluster was identified, the integrity of which would be required for cyclin binding.

\section{Expression of cdc2 mutants affecting cyclin binding in fission yeast}

In order to analyse the physiological effects of $c d c 2$ mutations which alter the binding to cyclin we overexpressed these mutant proteins in the fission yeast Schizosaccharomyces 

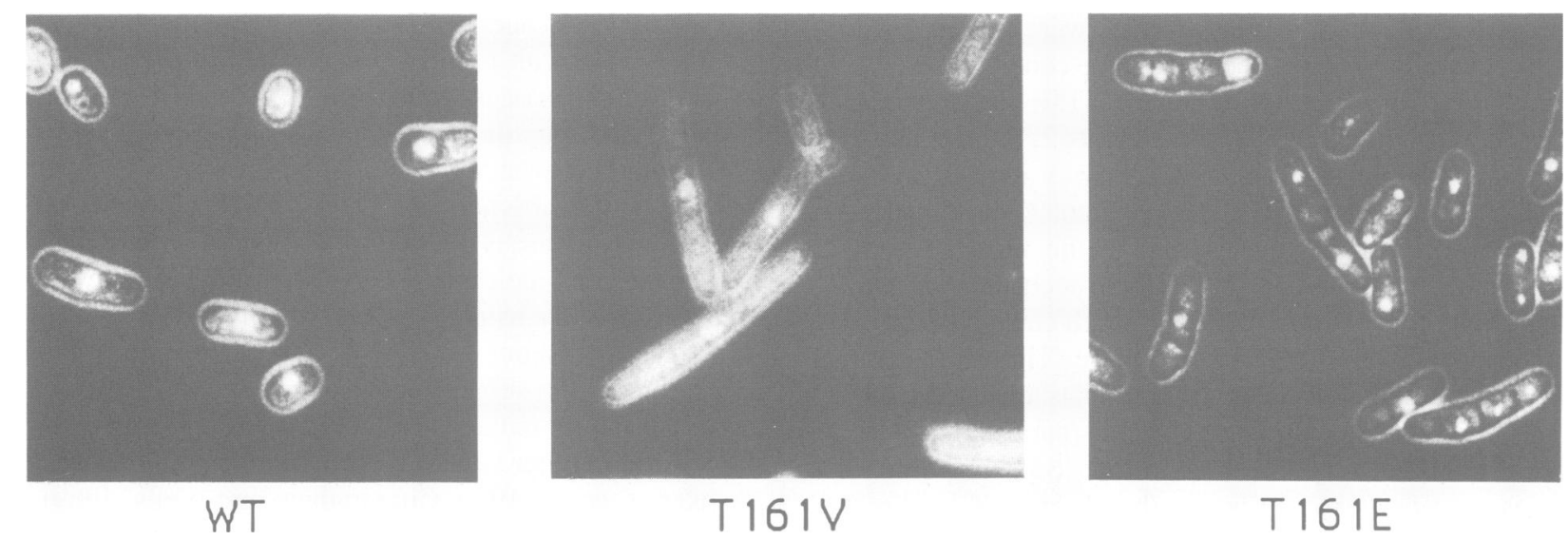

Fig. 6. Phenotypes of threonine mutations expressed in S.pombe. Phase contrast images of DAPI (4'-6-diamidino-2-phenylindole) stained S.pombe SP200 cells transformed with a plasmid overexpressing the human wild-type cdc2 gene or the mutant proteins cdc2-T161V and cdc2-T161E. Cells were observed $24 \mathrm{~h}$ after release of promoter repression, i.e. after $14 \mathrm{~h}$ of protein overexpression.

pombe. Overexpression was obtained under the control of a powerful thiamine repressible promoter (Maundrell, 1990) (Basi et al., manuscript in preparation). We tested the ability of the mutant proteins to rescue an S.pombe strain carrying a temperature-sensitive $c d c 2$ mutation, or to act as a dominant negative mutant (Herskowitz, 1987) in a wild-type strain. The results of these experiments are summarized in Table I. Overexpression of the wild-type human $c d c 2$ (Figure 6) led to the appearance of 'wee' cells, an indication of premature entry into mitosis (Nurse, 1975; Fantes, 1983). This was also found when S.pombe $c d c 2$ was overexpressed using a similar inducible promoter system (Fleig and Nurse, 1991). The wild-type human $c d c 2$ gene fully rescued a strain carrying the temperature-sensitive $c d c 2-33$ mutation. Since the overexpression of the protein was performed using a replicative vector, the presence of few elongated cells is probably due to plasmid losses or rearrangements. Mutations which affected cyclin binding were unable to rescue a $c d c 2-33$ strain; transformants carrying these mutant genes displayed a classical ' $c d c^{-}$' phenotype when cultured at restrictive temperature, i.e. the cells were highly elongated and carried one single nucleus. An exception was the E8A, K9A, E12A mutant, which although not able to bind cyclin in vitro was still able to rescue a cdc2-33 strain in vivo. A lowered affinity between the E8A, K9A, E12A mutant and cyclin could be responsible for the lack of association in vitro, yet the large overexpression of the mutant protein in S.pombe would still allow cell cycle progression. None of the cluster mutations generated displayed a dominant lethal phenotype. We also tested mutants showing a somewhat lower binding to cyclin A-Sepharose (60-80\% as compared with wildtype) and found that all of them were able to rescue $c d c 2$ ts mutations.

With regard to point mutations at the phosphorylation sites, the T161V mutation caused a lethal phenotype when overexpressed in a wild-type background (Figure 6), suggesting that this protein was still able to bind an essential cellular component, thereby titrating it away from the wild-type S.pombe cdc2. A substitution of the essential Thr161 with a glutamate, in an attempt to mimic phosphorylation, gave different results. Cells were slightly elongated and formed multiple septa. In addition, the nuclei remained condensed and were abnormally distributed between 'daughter' compartments of the cell (Figure 6). In some cases, the three chromosomes were distinguishable and were also abnormally segregated. This phenotype clearly indicates that the presence of a permanent negative charge in position 161 perturbs the normal occurrence of mitosis. Further characterization of this phenotype is under way.

\section{Discussion}

A necessary step towards understanding how cdc2 is regulated is to determine the structural requirements that mediate the stimulation of its activation. Since binding to cyclins is a key event for the temporal regulation of cdc2 kinase activity, we have begun to investigate how the two molecules interact. Two binding assays were developed to analyse the requirements for the binding of $\mathrm{A}$ and $\mathrm{B}$ type cyclins to cdc2. In both cases, we show that the binding efficiency was considerably increased when cyclin and cdc2 were incubated with a Xenopus egg extract. The interaction between human cyclin $\mathrm{A}$ and cdc2 was performed using recombinant cyclin A coupled to Sepharose as a matrix to precipitate cdc2. Since we could not produce a similar reagent with human cyclin $B$, its interaction with cdc2 was analysed using in vitro translated cyclin $B$. In this case, the precipitation of the cyclin $\mathrm{B}-\mathrm{cdc} 2$ complex was performed using an antiserum directed against the carboxy-terminus of human cdc2. The level of association between cdc2 and cyclin B was difficult to quantify using this method, and therefore we preferentially used cyclin A-Sepharose for the binding assay. Nevertheless, on a qualitative basis, the binding requirements for cyclin $\mathrm{B}$ on $\mathrm{cdc} 2$ were found to be similar to those presented here for cyclin A.

We have discovered that tight binding of $\mathrm{cdc} 2$ to cyclin A or B only occurs when an essential phoshorylation event has taken place in the egg extract. This shows that at least one kinase important for cdc2-cyclin interaction is activated in these extracts. Moreover, this phosphorylation event involves Thr161, and possibly other unidentified residues in the cdc2 or cyclin proteins. Substitutions of Thr14, Tyr15 or Ser277 with non-phosphorylatable amino acids did not affect the binding of cdc2 to cyclin, whereas Thr161 mutation completely abolished the binding. We have also shown that preincubation of human cdc2 in an extract devoid of cyclins even in the presence of phosphatase inhibitors did not increase its binding to cyclin molecules added afterwards 


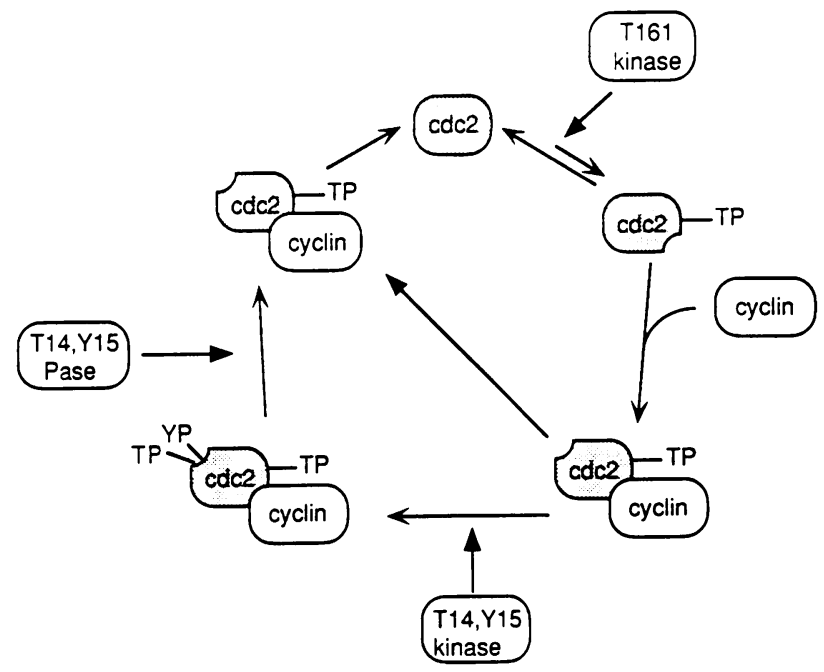

Fig. 7. A model for the activation of a cdc2-cyclin complex. In the absence of cyclin, a small proportion of the cdc2 molecules is phosphorylated. Cyclin binding stabilizes cdc2 phosphorylation, and allows it to be active. Depending on the particular cyclin it binds to, cdc2 may be targeted to an inhibitory T14,Y15 kinase before its full activation.

in the presence of kinase inhibitors. This almost eliminates the possibility that a phosphorylation on cdc 2 , essential for its tight binding to cyclin, occurs in the absence of cyclin. Several possibilities should be considered in order to explain the requirements of phosphorylation for cdc 2 binding to cyclins: (i) cdc2 must be phosphorylated (probably on Thr161), (ii) cyclin could be phosphorylated, although cyclin preincubation with a cellular extract was not sufficient to allow binding, (iii) an unidentified component could be phosphorylated, or (iv) a combination of all three possibilities is required. Our data tend to favour the model shown in Figure 7 , in which cdc 2 and cyclins have a weak affinity in the absence of phosphorylation. This would account for the low binding always observed in the absence of an egg extract. cdc 2 phosphorylation could favour its interaction with cyclin, driving the equilibrium of the reaction towards the phosphorylated and bound state. It is of interest to know how the phosphorylation on the sites required for tight binding is regulated. Is it by protection of the sites from dephosphorylation? Is it by activation of kinases? Or is it by making the substrates available for phosphorylation? In any case integrity of Thr161 is clearly required for the interaction between cdc 2 and A or B cyclin. This threonine is located within a region conserved in all protein kinases (Hanks et al., 1988) which contains an 'autophosphorylation' site. In this region are located Tyr416 of c-src and Thr197 of the catalytic subunit of cAMP-dependent protein kinase (PKA). In S.cerevisiae, substitution of Thr241 in PKA (analogous to Thr197 of bovine PKA) with Ala reduces its affinity for the regulatory subunit (Levin and Zoller, 1990). It will be challenging to study these various hypotheses in further detail as assays for Thr 161 phosphorylation are developed.

We have also extended our analysis by mutagenizing entire clusters of charged amino acids and found that the aminoterminal third of the cdc 2 molecule is required for cyclin binding. This includes the ATP-binding site and the homologous residue to Lys71 of PKA, a residue essential for the catalytic activity of all protein kinases. If phosphorylation on Thr161 occurred as a result of an autophosphorylation reaction, then a mutation blocking the catalytic activity of cdc 2 would inhibit cdc 2 phosphorylation and as a consequence, its binding to cyclin. Contrary to studies performed with enzymes such as PKA, it will not therefore be easy to distinguish between structural requirements for cdc 2 activity as opposed to requirements for cyclin binding.

Some additional mutations affecting binding are located within the conserved 'PSTAIR' sequence (amino acids $42-57$ in human cdc2), present in all cdc2 homologues, but not in other protein kinases. This region is predicted to reside on the surface of the cdc2 protein (Carr et al., 1989), and may be involved in the interaction with cyclin. Fleig and Nurse (1991) have identified a dominant negative mutation of $c d c 2$ in $S$. pombe caused by a single amino acid substitution (A48V) within the PSTAIR region, confirming the need for absolute conservation of this region for cdc2 function. Interestingly, anti-cdc 2 antibodies directed against the 16 amino acid PSTAIR consensus precipitate monomeric and inactive cdc2 kinase, suggesting that the PSTAIR may indeed be an interaction site for cyclin (Pines and Hunter, 1989; M.Pagano and G.Draetta, unpublished). A peptide mimicking this sequence might be a good competitor for cyclin binding to cdc 2 . However, we detected only $30 \%$ inhibition of binding when cyclin A-Sepharose was preincubated in the presence of $10 \mathrm{mM}$ PSTAIR peptide before incubation with cdc2 (data not shown). This may be due to a much lower affinity of the PSTAIR peptide for cyclin A than that of cdc2. It clearly appears that a phosphorylation-dephosphorylation cycle of Thr161 plays a major role in regulating the kinase activity of cdc2. Recent findings (Lee et al., 1991) have suggested that Thr161 is a substrate for a form of protein phosphatase 2A (PP2A) which leads to the inactivation of the cdc2 kinase. Our results do not show that PP2A acts before cyclin binding by dephosphorylating the sites required for cdc2-cyclin association. Indeed, okadaic acid does not favour binding of cyclin to cdc 2 . But we cannot exclude the possibility that the situation is different at the end of mitosis when cyclin has been degraded. It is possible that at this stage, monomeric cdc 2 is rapidly dephosphorylated on threonine and inactivated. Indeed, in Xenopus egg extracts in which histone $\mathrm{H} 1$ kinase is activated in the presence of okadaic acid, the kinase remains partially active after cyclin degradation (Félix et al., 1990a). Several laboratories have argued that a histone $\mathrm{H} 1$ kinase activity is associated with monomeric cdc2 (Brizuela et al., 1989), or with cdc2 preparations containing degradation products of cyclin (Labbé et al., 1989a). In S.pombe, an active monomeric form of cdc2 has also been identified (S.Moreno and P.Nurse, personal communication). If Thr 161 phosphorylation is important for the activity of cdc2 kinase, replacement of this residue by a negatively charged amino acid should mimic the charge of a phosphate group and produce a kinase that was at least partially active. In this respect, the phenotype of yeast cells overexpressing a cdc 2 mutant in which Thr161 has been changed to Glu is very interesting. Chromosomes remain condensed and the cells generate several septa showing disorganized and unevenly distributed chromosomes, as if late mitotic events were kept turned on. One possible interpretation for this observation is that a monomeric form of $\mathrm{cdc} 2$ remains active at the end of mitosis because the negative charge at position 161 cannot be regulated. It remains to be shown that in vivo, the T161E cdc2 mutant is active when not complexed to cyclin. It is 
worth mentioning that we found histone $\mathrm{H} 1$ kinase activity associated with the T161E cdc2 expressed in S.pombe, while no activity was found in T161V immunoprecipitates (data not shown). The fact that T161V mutation has a dominant lethal phenotype is interesting. This suggests that the mutant protein, like the wild-type cdc2, binds another component in addition to cyclin. It is for example clear that the T161V mutant can normally bind the sucl protein (Ducommun,B., Brambilla,P. and Draetta,G., submitted). Therefore sucl might be the protein that is titrated away from cdc 2 and that is responsible for this phenotype. It could also be that mutant T161V cdc2 weakly binds cyclin and that its overexpression prevents the endogenous cdc 2 from binding to cyclin.

Thr161 phosphorylation was found to be required for both cyclin A and cyclin B binding to cdc2. This phosphorylation occurs already in the $S$ phase of the cell cycle (Krek and Nigg, 1991) and it parallels the accumulation of cyclin A in human cells (M.Pagano and G.Draetta, unpublished results). It will be extremely interesting to test whether the association of the putative mammalian $G_{1}$ cyclins (Matsushime et al., 1991; Motokura et al., 1991; Xiong et al., 1991) with cdc2 (or a cdc2-like molecule) also requires an intact Thr161. The reversible phosphorylation of cdc 2 on Thr161 would ensure that cdc 2 activation only occurs upon binding to a regulatory subunit, which then targets the kinase to the proper substrate or cellular compartment. Thr161 phosphorylation may represent the posttranslational modification of cdc2 potentially required for preventing a cell from replicating its DNA more than once per cell cycle (Broek et al., 1991).

\section{Materials and methods}

\section{Site-directed mutagenesis}

The coding sequence for the human $c d c 2$ gene was cloned in the pT7F1A expression vector (Kuret $e t$ al., 1988). Uridylated single-stranded DNA was prepared according to Sambrook et al. (1989) with M13K07 helper phage infection in BW313 Escherichia coli strain. Oligonucleotide directed mutagenesis was performed as described (Kunkel et al., 1987; Zoller and Smith, 1987) and colonies obtained were screened by DNA sequencing.

\section{In vitro transcription and translation procedures}

In vitro transcription of the human $c d c 2$ mutants cloned in PT7F1A was performed using the Riboprobe kit (Promega). The transcriptional mixture was: $1 \times$ polymerase buffer (Promega), $0.5 \mathrm{mM}$ rNTPS, $10 \mathrm{mM}$ DTT, $0.1 \mathrm{U} / \mu \mathrm{l}$ RNasin, $0.04 \mathrm{U} 7 \mathrm{mGpppG}$ (Boehringer), $1.2 \mathrm{U} / \mu \mathrm{l} \mathrm{T7}$ polymerase, $0.5 \mu \mathrm{g}$ template DNA in a final volume of $10 \mu \mathrm{l}$. The reaction was performed at $37^{\circ} \mathrm{C}$ for $1 \mathrm{~h}$. The reaction mixture was diluted to $100 \mu \mathrm{l}$ and the RNA was subsequently extracted by phenol and chloroform/isoamyl alcohol extractions. After ethanol precipitation in the presence of $0.3 \mathrm{M}$ sodium acetate, $\mathrm{pH} 5.4$ and $1 \mu \mathrm{g}$ of glycogen, the RNA was resuspended in $10 \mu \mathrm{l}$ of nuclease-free water containing $1 \mathrm{U}$ of RNasin (Promega).

In vitro translations were performed using rabbit reticulocyte lysate (Promega) according to the instructions of the manufacturer. Trans ${ }^{35} \mathrm{~S}$-label was purchased from ICN. The translation mixture was supplemented with $200 \mathrm{mM}$ potassium acetate, $1.2 \mathrm{mM} \mathrm{MgCl} 2$. The reaction was performed at $30^{\circ} \mathrm{C}$ for $90 \mathrm{~min}$ and immediately used for binding assay.

\section{Xenopus egg extract preparation}

Xenopus laevis females were purchased from the Service d'élevage d'Amphibiens, CNRS (France) and primed 3-7 days before use with $100 \mathrm{U}$ pregnant mare serum gonadotrophin (Intervet, France). They were then injected the day before with $1500 \mathrm{U}$ human chorionic gonadotrophin (Sigma) and the eggs were collected overnight in $0.1 \mathrm{M} \mathrm{NaCl}$. Egg extracts were prepared basically as described (Félix et al., 1990a). The eggs were dejellied with $2.5 \%$ cysteine $-\mathrm{HCl}(\mathrm{pH} 7.8)$ and washed extensively with modified Ringer's MMR/4 (25 mM NaCl, $0.4 \mathrm{mM} \mathrm{KCl}, 0.25 \mathrm{mM} \mathrm{MgSO}_{4}, 0.5 \mathrm{mM}$ $\mathrm{CaCl}_{2}, 1.25 \mathrm{mM}$ HEPES, $25 \mu \mathrm{M}$ EDTA, pH 7.2). They were activated by an electric shock, incubated at $20^{\circ} \mathrm{C}$ for $40 \mathrm{~min}$ and then transferred to a SW 50.1 tube filled with ice-cold acetate buffer $(100 \mathrm{mM}$ potassium acetate, $2.5 \mathrm{mM}$ magnesium acetate, $60 \mathrm{mM}$ EGTA, $5 \mu \mathrm{g} / \mathrm{ml}$ cytochalasin D, $1 \mathrm{mM}$ DTT, pH 7.2). Excess acetate buffer was removed. The eggs were crushed by centrifugation at $10000 \mathrm{~g}(9000 \mathrm{r}$.p.m. in an SW 50.1 rotor) for $10 \mathrm{~min}$ at $4^{\circ} \mathrm{C}$ in an L5-65 Beckman centrifuge at maximum acceleration rate. The cytoplasmic material between the upper lipid layer and the yolk pellet was collected and recentrifuged in the SW 50.1 rotor at $100000 \mathrm{~g}\left(30000 \mathrm{r}\right.$.p.m.) for $60 \mathrm{~min}$ at $4^{\circ} \mathrm{C}$. The supernatant was collected and kept as 50-100 $\mu$ l aliquots in liquid nitrogen. These supernatants contain $30-40 \mathrm{mg} / \mathrm{ml}$ proteins. In order to remove most of the endogenous cdc2 protein contained in these extracts, two successive incubation with p13-Sepharose were performed as follows: 1 vol of p13-Sepharose beads (Brizuela et al., 1989) were washed twice in buffer A: $100 \mathrm{mM}$ potassium acetate, $2.5 \mathrm{mM}$ magnesium acetate, $\mathrm{pH} 7.2,1 \mathrm{mM}$ DTT, $0.1 \mathrm{mM}$ PMSF, $1 \mu \mathrm{g} / \mathrm{ml}$ leupeptin, $10 \mu \mathrm{g} / \mathrm{ml}$ soybean trypsin inhibitor, $1 \mu \mathrm{g} / \mathrm{ml}$ aprotinin and $10 \mu \mathrm{g} / \mathrm{ml}$ TPCK (tosyl phenylalanine chloromethyl ketone) and incubated with 1 vol of Xenopus egg extract and 1 vol buffer A for $30 \mathrm{~min}$ a $4^{\circ} \mathrm{C}$ on a rotator. cdc2-depleted Xenopus egg extracts were recovered after two successive $10 \mathrm{~min}$ centrifugations (Eppendorf table top centrifuge, 14000 r.p.m.). During a preliminary experiment to optimize the binding assay, we found that this cdc2 depletion step (Félix et al., 1989) increases the binding efficiency of exogenous cyclin to exogenous cdc2.

\section{Binding assay}

Human cyclin A was expressed in E.coli. The protein was purified from the soluble fraction using non-denaturing chromatography techniques (M.Pagano and G.Draetta, in preparation). It was coupled to $\mathrm{CNBr}$-activated Sepharose (Pharmacia) according to the manufacturer. The assay consisted of incubating in vitro translated human cdc2 $\left({ }^{35} \mathrm{~S}\right]$ methionine labelled) with either in vitro translated human cyclin B or cyclin A-Sepharose in the presence of a Xenopus egg extract for $30 \mathrm{~min}$ at $25^{\circ} \mathrm{C}$. The level of either cyclin B associated with a human cdc2 immunoprecipitate or cdc2 associated to cyclin $\mathrm{A}$-Sepharose precipitate was quantified.

To analyse human cdc 2 binding to cyclin $\mathrm{B}, 5 \mu \mathrm{l}$ of each in vitro translated protein were mixed together and incubated for $30 \mathrm{~min}$ at $25^{\circ} \mathrm{C}$ with $20 \mu \mathrm{l}$ of Xenopus egg extract with gentle shaking every $10 \mathrm{~min}$. The reaction mixture was then diluted to $1 \mathrm{ml}$ with buffer $\mathrm{B}(50 \mathrm{mM}$ Tris $-\mathrm{HCl} \mathrm{pH} 8.0$. $250 \mathrm{mM} \mathrm{NaCl}, 50 \mathrm{mM}$ sodium fluoride, $5 \mathrm{mM}$ EDTA, $0.1 \mathrm{mM}$ sodium orthovanadate, $0.1 \%$ Triton X-100, $1 \mathrm{mM}$ DTT, $0.1 \mathrm{mM}$ PMSF, $1 \mu \mathrm{g} / \mathrm{ml}$ leupeptin, $10 \mu \mathrm{g} / \mathrm{ml}$ soybean trypsin inhibitor, $1 \mu \mathrm{g} / \mathrm{ml}$ aprotinin and 10 $\mu \mathrm{g} / \mathrm{ml}$ TPCK) and immunoprecipitations were performed using a polyclonal serum raised against the human cdc2 carboxy-terminus (Draetta and Beach, 1988). After a further $20 \mathrm{~min}$ incubation in the presence of protein A-Sepharose, precipitates were washed three times with $1 \mathrm{ml}$ of buffer B. The final pellets were resuspended in Laemmli sample buffer and electrophoresed on $12.5 \%$ SDS - polyacrylamide gels. Gels were treated with Enlightening (NEN), dried and exposed to X-Omat AR film (Kodak).

To analyse cdc2 binding to cyclin A, a 1:3 mixture of cyclin ASepharose:BSA - Sepharose (or only BSA-Sepharose in controls) was washed twice in buffer A. For each assay, $20 \mu \mathrm{l}$ (dry volume) of these mixed beads were added to $5 \mu \mathrm{l}$ of translation mix and $20 \mu \mathrm{l}$ of Xenopus egg extract and incubated for $30 \mathrm{~min}$ at $25^{\circ} \mathrm{C}$ with gentle shaking every $10 \mathrm{~min}$. The reaction mixture was then diluted to $1 \mathrm{ml}$ with buffer $\mathrm{B}$ and the Sepharose beads pellet was washed three times and treated as above. The level of cdc2 retained by the cyclin A-Sepharose matrix was quantified using an LKB laser densitometer. The gels were not enhanced prior to drying in order to be able to detect easily the lower mobility forms of $\mathrm{cdc} 2$. The assay was optimized for maximal binding activity of cyclin to wild-type cdc2. The following important parameters were determined: (i) egg extracts collected $40 \mathrm{~min}$ rather than $10 \mathrm{~min}$ after activation; (ii) $30 \mathrm{~min}$ of incubation; (iii) two successive p13-Sepharose depletions of the extract; (iv) 1:1 dilution of the extract in buffer A; (v) assay performed at $25^{\circ} \mathrm{C}$. For some specific experiments, the incubation was done in the absence of the Sepharose beads mix. The reaction was stopped by addition of $10 \mathrm{mM}$ EDTA and after $5 \mathrm{~min}$ on ice, cyclin A-Sepharose was also added. Binding was allowed to proceed for a further $60 \mathrm{~min}$ at $4^{\circ} \mathrm{C}$. The samples were then diluted to $1 \mathrm{ml}$ with buffer $\mathrm{B}$ and processed as described above.

Since the efficiency of the transcription/translation reactions varies among different cDNAs, the amount of total precipitable protein in the assay was determined by performing immunoprecipitation on an identical amount of translation mixture. Autoradiograms of the SDS gels were scanned using an LKB laser densitometer. For each binding assay a ratio between the amount of cdc2 bound to cyclin and the total amount of cdc2 present in the assay was obtained. We assigned a $100 \%$ value for this ratio in the wild-type cdc2 protein and nomalized all the other mutants to this value. 


\section{Expression of mutant proteins in S.pombe}

Human wild-type and mutant cdc2s were subcloned as an NdeI-BamHI cassette in the thiamine repressible replicative shuttle vector pREP42 (Maundrell, 1990) (Basi et al., in preparation). The ura 4 marker was used for selection. The S.pombe strains SP200 $\left(h^{-\mathrm{s}}\right.$ leul.32 ura4 ade210) and SP356 $\left(h^{+\mathrm{n}}\right.$ leul-32 ura4 ade6-210 cdc2-33) were transformed with the pREP42 plasmid constructions. The promoter was kept under repressed conditions by addition of $4 \mu \mathrm{M}$ thiamine to the solid and liquid media. Derepressed conditions were obtained by replica plating on media without thiamine or in liquid culture by washing twice the cells in minimal medium and growing them in the absence of thiamine. Induction of the proteins started to be observed after $\sim 10 \mathrm{~h}$ (Basi et al., manuscript in preparation). Cells were cultured in complete medium (YEA: $0.5 \%$ yeast extract, $3 \%$ glucose, $75 \mu \mathrm{g} / \mathrm{ml}$ adenine) or in minimal medium (PMA) (Moreno et al., 1991).

For phase contrast microscopy, cells were collected $24 \mathrm{~h}$ after the removal of the thiamine i.e. $\sim 14 \mathrm{~h}$ of full activity of the promoter. After $30 \mathrm{~min}$ fixation in the presence of $3.7 \%$ formaldehyde, cells were washed once with PBS, resuspended in PBS and mounted on a cover slip coated with poly-lysine. Coverslips were inverted on $2 \mu \mathrm{l} 50 \%$ glycerol containing $2 \mu \mathrm{g} / \mathrm{ml}$ DAPI (4'-6-diamidino-2-phenylindole) (Moreno et al., 1991). Observations were performed on a Leitz Aristoplan microscope.

\section{2-D gel electrophoresis}

Samples for high resolution 2-D gel electrophoresis (Garrels, 1983) were prepared as described (Franza, 1987; Giordano, 1989). The autoradiographs in Figure 4 were exposed for 3 days (panels A and B) or for 5 days (panels C and D).

\section{Acknowledgements}

We are grateful to Mark Zoller for suggesting the use of charged to alanine scanning mutagenesis for studying cdc2 structure - function relationships. We thank David Beach for his gift of yeast strains and other invaluable reagents. Dirk Bohmann and Catherine Chavrier are thanked for their advice on in vitro translation procedures. Monika Stein is thanked for technical assistance. Jon Pines and Christian Brechot are thanked for supplying human cyclin A vectors, and Gabriele Basi for plasmid pREP42. Michele Pagano is gratefully acknowledged for providing cyclin A-Sepharose. All members of our laboratories are thanked for their interests and contribution to this work. Sara Courtneidge and Thomas Graf are thanked for valuable comments on the manuscript. B.R.F. was supported by a grant from the Freeman Charitable Trust. E.K. was supported by a grant from the Human Frontier Science Program. M.Félix is a fellow of the CNRS. G.D. was supported in part by NATO grant no. CGR900652.

\section{References}

Ashkenazi,A., Presta,L., Marsters,S., Camerato,T., Rosenthal,K. Fendly,B. and Capon,D. (1990) Proc. Natl. Acad. Sci. USA, 87. $7150-7154$.

Brizuela,L., Draetta,G. and Beach,D. (1989) Proc. Natl. Acad. Sci. USA, 86, $4362-4366$.

Broek,D., Bartlett,R., Crawford,K. and Nurse,P. (1991) Nature, 349. 388-393.

Carr,A.M., MacNeill,S., Hayles,J. and Nurse,P. (1989) Mol. Gen. Genet. . 218, $41-49$.

Cunningham,B. and Wells,J. (1989) Science, 244, 1081-1085

Draetta,G. and Beach,D. (1988) Cell, 54, 17-26.

Draetta,G., Piwnica,W.H., Morrison,D., Druker.B., Roberts,T. and Beach,D. (1988) Nature, 336, 738-744.

Draetta,G., Luca,F., Westendorf,J., Brizuela,L., Ruderman,J. and Beach,D. (1989) Cell, 56, 829-838.

Ducommun,B., Tollon,Y., Garès,M., Beach,D. and Wright,M. (1990) J Cell Sci., 96, 683-689.

Dunphy,W. and Newport,J. (1989) Cell, 58, 181-191.

Fantes,P. (1983) Nature, 302, 153-155.

Félix,M.-A., Pines,J., Hunt.T. and Karsenti.E. (1989) EMBO J.. 8. 3059-3069.

Félix,M.A., Cohen,P. and Karsenti,E. (1990a) EMBO J., 9, 675-683.

Félix,M.A., Labbé,C., Dorée,M., Hunt,T. and Karsenti,E. (1990b) Nature, 346, 379-382.

Fleig,U. and Nurse,P. (1991) Mol. Gen. Genet., 226, 432-440.

Franza,B.R.,Jr, Joseph,S.F., Gilman,M.Z., Ryan,W. and Clarkson,B. (1987) Nature, 330, 391-395.

Garrels,J.I. (1983) Methods Enzymol., 100B, 411-439.
Gautier,J., Matsukawa,T., Nurse.P. and Maller,J. (1989) Nature, 339, 626-629.

Gautier,J., Minshull,J., Lohka,M.M.G., Hunt,T. and Maller,J.L. (1990) Cell, 60, 487-494.

Gibbs,C.S. and Zoller,M.J. (1991) J. Biol. Chem., 266, 8923-8931.

Giordano,A., Whyte,P., Harlow,E., Franza,B.R., Beach,D. and Draetta,G. (1989) Cell, 58, $981-990$

Gould,K.L. and Nurse,P. (1989) Nature, 342, 39-45.

Gould,K.L., Moreno,S., Tonks,N.K. and Nurse,P. (1990) Science, 250, 1573-1575.

Hanks,S.K., Quinn,A.M. and Hunter,T. (1988) Science, 241, 42-52.

Herskowitz,I. (1987) Nature, 329, 219-222.

Hunt,T. (1989) Curr. Opin. Cell Biol., 1, 286-274.

Jessus, C., Ducommun,B. and Beach,D. (1990) FEBS Lett., 266, 4-8.

Krek,W. and Nigg,E. (1991) EMBO J., 10, 305-316.

Kunkel,T.A., Roberts,J.D. and Zakur,R.A. (1987) Methods Enzymol., 154, 367-382.

Kuret,J., Johnson,K.E., Nicolette,C. and Zoller,M.J. (1988) J. Biol. Chem., $263,9149-9154$

Labbé,J.C., Capony,J.P., Caput,D., Cavadore,J.C., Derancourt,J., Kaghdad,M., Lelias,J.M., Picard,A. and Dorée,M. (1989a) EMBO J. 8, 3053-3058.

Labbé,J.C., Picard,A., Peaucellier,G., Cavadore,J.C., Nurse,P. and Dorée,M. (1989b) Cell, 57, 253-263.

Lee,T.H., Solomon,M.J., Mumby,M.C. and Kirschner,M.W. (1991) Cell, 64, 415-424.

Levin,L. and Zoller,M. (1990) Mol. Cell. Biol., 10, 1066-1075.

Matsushime,H., Roussel,M., Ashmun,R. and Sherr,C.J. (1991) Cell, 65, $701-713$.

Maundrell,K. (1990) J. Biol. Chem., 265, 10857-10864.

Minshull,J., Golsteyn,R., Hill,C. and Hunt,T. (1990) EMBO J., 9, 2865-2875.

Moreno,S., Klar,A. and Nurse,P. (1991) In Gutrie,C. and Fink,G. (eds), Guide to Yeast Genetics and Molecular Biology. Academic Press, New York, Vol. 194, pp. 795-826.

Morla,A., Draetta,G., Beach,D. and Wang,J.Y.J. (1989) Cell, 58, 193-203.

Motokura,T., Bloom,T., Kim,Y.G., Jueppner,H., Ruderman,J., Kronenberg,H. and Arnold,A. (1991) Nature, 350, 512-515.

Nurse,P. (1975) Nature, 256, 547-551.

Pines,J. and Hunter,T. (1989) Cell, 58, 833-846.

Pines,J. and Hunter,T. (1990) Nature, 346, 760-763.

Pondaven,P., Meijer,L. and Beach,D. (1990) Genes Dev., 4, 9-17.

Richardson,H., Wittenberg,K., Cross,F. and Reed,S. (1989) Cell, 59, $1127-1133$

Sambrook,J., Fritsch,E.F. and Maniatis,T. (1989) Molecular Cloning: $a$ Laboratory Manual. Cold Spring Harbor Laboratory Press, Cold Spring Harbor, NY.

Simanis,V. and Nurse,P. (1986) Cell, 45, 261-268.

Solomon,M.J., Glotzer,M., Lee,T.L., Philippe,M. and Kirschner,M.W. (1990) Cell, 63, 1013-1024.

Xiong,Y., Connolly,T., Futcher,B. and Beach,D. (1991) Cell, 65, 691-699.

Zoller,M.J. and Smith,M. (1987) Methods Enzymol., 154, 329-350.

Zoller,M., Nelson,N. and Taylor,S. (1981) J. Biol. Chem., 256, $10837-10842$.

Received on May 23, 1991; revised on July 3, 1991 